\title{
Characterization of Polyamide 66 Membranes Prepared by Phase Inversion Using Formic Acid and Hydrochloric Acid Such as Solvents
}

\author{
Patrícia Poletto*, Jocelei Duarte, Mônica Beatriz Thürmer, Venina dos Santos, Mára Zeni \\ Centro de Ciências e Tecnologia, Universidade de Caxias do Sul-UCS, \\ CP 1130, CEP 95070-560, Caxias do Sul, RS, Brasil
}

Received: May 5, 2011; Revised: August 15, 2011

\begin{abstract}
The membranes properties prepared from water/formic acid (FA)/ polyamide 66 (PA66) and water/hydrochloric acid $(\mathrm{HCl})$ /polyamide 66 (PA 66) systems has been studied. The different solvents interact distinctly with the polymer, affecting the membrane morphology. The asymmetric structure of the membranes showed a dense top layer and a porous sublayer. The membranes $\mathrm{M}-\mathrm{HCl}$ prepared from $\mathrm{HCl} / \mathrm{PA} 66$ system showed a larger dense layer (around $23 \mu \mathrm{m}$ ) in compared to those prepared from FA/PA 66 system (M-FA) (around $10 \mu \mathrm{m}$ ). The membrane morphology was a determinant factor in results of water absorption, porosity and pure water flux. The lower thickness of dense layer in M-FA membranes resulted in a higher water absorption and, consequently, porosity, approximately $50 \%$, compared with $\mathrm{M}-\mathrm{HCl}$ membranes, approximately $15 \%$. The same trend was observed to permeate flux, the lower thickness of dense layer higher pure water flux.
\end{abstract}

Keywords: polyamide 66, porous membrane, asymmetric membranes

\section{Introduction}

The preparation and application of polymeric membranes obtained by phase inversion method is reported in the literature by many authors ${ }^{1-7}$. The mechanism of phase inversion is a determinant factor in the membranes morphology and in understanding the phenomena involved in their synthesis. The conditions for the membranes preparation (polymer concentration, type of solvent, time and temperature of casting and composition of coagulation bath) may directly influence their morphology and transport properties. The choice of these conditions determines the formation of symmetric or asymmetric membranes with diverse pore structures and the characteristics of transport properties ${ }^{8}$.

Young et al. ${ }^{9}$, evaluated the effect of temperature on the membranes formation from polyamide 66 (PA 66) and found that slight alterations on solvent evaporation temperature also affected the morphology and crystalline structure of the membrane.

The composition of the coagulation bath, which has a direct effect on the mass transfer rate between solvent and non-solvent ${ }^{10}$, the use of additives in the polymer solution ${ }^{11-15}$ and the effect of different solvents and non-solvents ${ }^{16}$ cause significant modifications on morphology and permeability of polymeric membranes. In our previous work ${ }^{15}$ was showed that the addition of a second polymer with high molecular weight (polyvinyl pyrrolidone) in PA 66 membranes enhanced the morphological structure, decreasing the thickness of dense layer and increased permeate water flux.

The miscibility, crystallinity and morphology of membranes from polyamide/poly(vinylalcohol) (PVA) blend materials were studied by AI-Rawajfeh et al. ${ }^{4,5}$. The PVA addition had a positive effect on increasing hydrophilicity and in morphology of nanofiltration and reverse osmosis application. By Lin et al. ${ }^{10}$ membranes with nanometer-scale crystalline morphology were obtained by varying the composition of the polymer solution (non-solvent/solvent/ polyamide 66) and the coagulation bath (non-solvent and solvent). Yao et al. ${ }^{3}$ prepared membranes of polyamide 6 using hydrochloric acid as solvent and found that the change in non-solvent, different morphological structures were obtained resulting in variations of pure water flux. Using the most basic solutions to the water, such as pyridine and ammonium hydroxide, the finger pore structure was formed and using alcoholic solutions the sponge-like structure was obtained.

Membranes prepared from polyamide/ formic acid are usually described in literature $e^{4,5,7,10,17,18}$, but few studies ${ }^{3}$ and our previous works ${ }^{15,19}$ have reported the preparation of membranes from PA 66/ hydrochloric acid. This paper aims to show that the solvent has an important role in the preparation of polymeric membranes and the characteristics of each solvent impose different morphologies. The membrane-forming systems consisting of water/formic acid/PA 66 and water/hydrochloric acid/PA66 were used for obtaining the polymeric membrane. The resulting membranes were characterized by scanning electron microscopy (SEM), water content, porosity and pure water flux.

\section{Experimental}

\subsection{Materials}

Commercial PA 66 from Alfa Chem. Co., Brazil, Mw $161,000 \mathrm{~g} \cdot \mathrm{mol}^{-1}$, was received in pellet form. The hydrochloric acid ( $\mathrm{HCl}$ ) (Merck Brazil, 37\%) and formic acid (FA) (Merck Brazil, 98\%) was used as the solvent and used as received. Distilled-deionized water was used as the nonsolvent for PA 66.

\subsection{Membrane preparation}

Polymer solutions of 20 wt. (\%) of PA 66 in $\mathrm{FA}$ and $\mathrm{HCl}$ were cast at room temperature $\left( \pm 23^{\circ} \mathrm{C}\right)$ on glass plates with a uniform thickness of $0.3 \mathrm{~mm}$ by a casting stainless steel knife. Different conditions at the evaporation stage have been tested in accordance with Table 1, which will be discussed in section 3.1. The solvent was evaporated and the glass plates were immersed in a coagulation bath 
Table 1. Preparation conditions of PA 66 membranes.

\begin{tabular}{|c|c|c|c|c|c|}
\hline \multirow[t]{2}{*}{ Membrane } & \multirow[t]{2}{*}{ Solvent } & \multicolumn{2}{|c|}{ Evaporation conditions } & \multicolumn{2}{|c|}{ Coagulation conditions } \\
\hline & & Time (minutes) & Temperature $\left({ }^{\circ} \mathrm{C}\right)$ & Time (minutes) & Temperature $\left({ }^{\circ} \mathrm{C}\right)$ \\
\hline \multirow[t]{2}{*}{ M-FA } & $\mathrm{HCOOH}$ & 5 & 20 & 120 & 15 \\
\hline & & 60 & 60 & 120 & 15 \\
\hline \multirow[t]{2}{*}{$\mathrm{M}-\mathrm{HCl}$} & $\mathrm{HCl}$ & 5 & 20 & 120 & 15 \\
\hline & & 60 & 60 & 120 & 15 \\
\hline
\end{tabular}

$\mathrm{M}-\mathrm{FA}=\mathrm{PA} 66$ membrane/formic acid $(\mathrm{HCOOH}), \mathrm{M}-\mathrm{HCL}=\mathrm{PA} 66$ membrane/HCl.

containing deionized water. Immediately after the contact with water, a variation in film color occurs, from clear to white, followed by the detachment of the film from the glass plate surface. After polymer coagulation, the prepared membranes were transferred to a second bath containing fresh distilled water to remove any residual solvent and then they were dried in air.

\subsection{Scanning electron microscopy (SEM) analysis}

The samples were initially fractured in liquid nitrogen and then gold-coated in a sputtering developed by laboratory of SEM (University of Caxias do Sul), for 1.5 minutes. The cross section morphology of the membranes was obtained by a Shimadzu SSX 550 scanning electron microscopy operated at $15 \mathrm{kV}$.

\subsection{Water content}

The membranes with an area of $1 \mathrm{~cm}^{2}$ were placed in closed flasks containing $50 \mathrm{~mL}$ of distilled water for 24 hours at a temperature of $23{ }^{\circ} \mathrm{C}$. The experiments were carried out in triplicate. The excess water on the surface of the wet membranes was removed with filter paper and the samples were weighed. Then, the samples were oven dried at $60{ }^{\circ} \mathrm{C}$ for 24 hours and weighed once again. In order to minimize the experimental errors, the water content of each sample was measured three times and the results were reported in average. From the results obtained from weighing the samples in wet and dry conditions, the amount of water absorbed by the membrane was calculated with the Equation 1:

$$
(\%) \text { water }=\frac{\mathrm{W}_{\mathrm{w}}-\mathrm{W}_{\mathrm{d}}}{\mathrm{W}_{\mathrm{d}}} \times 100
$$

where, $W_{w}$ is the weight of wet membranes $(\mathrm{g})$ and $W_{d}$ is the weight of dry membranes $(\mathrm{g})$.

\subsection{Porosity}

Porosity of the membranes was determined as follows ${ }^{12}$ :

$$
\mathrm{P}(\%)=\left[\frac{\mathrm{W}_{\mathrm{w}}-\mathrm{W}_{\mathrm{d}}}{\rho_{\mathrm{w}}}\right] \times \frac{100}{\mathrm{Ah}}
$$

where, $\rho_{w}$ is the density of pure water at room temperature $\left(\mathrm{g} \cdot \mathrm{cm}^{-3}\right), \mathrm{A}$ is the area of membranes $\left(\mathrm{cm}^{2}\right)$ and $\mathrm{h}$ is the thickness of membranes $(\mathrm{cm})$. This method of measuring porosity can only indicate overall porosity and is unable to discriminate the porosity of the skin layer from that of the porous sub-layer.

\subsection{Pure water flux measurements}

Pure water flux of the polyamide membranes were measured with a parallel flux type cell (area $0.0016 \mathrm{~m}^{2}$ ) at $101 \mathrm{kPa}$ and $\mathrm{J}_{\mathrm{w}}$ values were calculated using Equation $3^{12}$ :

$$
J_{\mathrm{w}}=\frac{V}{A \Delta t}
$$

where, $\mathrm{V}$ is the volume of the permeate $(\mathrm{L}), \mathrm{A}$ is membrane area $\left(\mathrm{m}^{2}\right)$ and $\Delta \mathrm{t}$ is the sampling time (hours).

\section{Results and Discussion}

\subsection{Membranes preparation conditions through the use of different solvents}

The system that forms the membranes (polymer/solvent/ non solvent) needs to be studied in detail in order to determine its best preparation conditions. Variations relative to preparation conditions are important factors that influence on the morphology and consequently on the membrane performance ${ }^{8,16}$.

The purpose of this work was to show that the use of different solvents during the preparation of polyamide 66 membranes resulted in different preparation conditions. In other words the solvent determined the best condition for the membrane preparation.

Most of the works ${ }^{7,10,18}$ utilize immersion precipitation when they use polyamide and formic acid. The membrane prepared through 5 minutes evaporation at $20{ }^{\circ} \mathrm{C}$ and posterior immersion into non solvent, showed a characteristic structure with the formation of the top layer and the porous sublayer (the membrane morphology will be discussed in the following section). The membrane formed at a temperature of $60{ }^{\circ} \mathrm{C}$ for 60 minutes showed a fragile structure that breaks off easily and at the same time it didn't show any pores formation that could be noticed all along its cross section (not shown here).

When $\mathrm{HCl}$ was used as solvent and evaporated for 5 minutes at $20{ }^{\circ} \mathrm{C}$, there did not appear the homogenous polymeric layer formation when immersed into non solvent. The prepared membrane morphology with 60 minutes evaporation at $60{ }^{\circ} \mathrm{C}$ and posterior immersion into non solvent was the condition where the polymeric film was obtained.

\subsection{Surface morphological analysis}

In a polymer/solvent/non-solvent system, the characteristics of phase separation determine the membrane structure. The membrane properties, which are correlated with morphology, are strongly influenced by the interaction between polymer and solvent ${ }^{20}$. Different solvents used in this work interact distinctly with the polymer, affecting the preparation conditions and the membrane morphological characteristics.

Formic acid is a weak organic acid whereas hydrochloric acid is a strong inorganic acid regarded as corrosive. However, the use of a strong acid, such as $\mathrm{HCl}$, does not change the chemical structure of polyamide as demonstrated in our previous work ${ }^{19}$.

The top surface of the membranes (Figure 1a and 1d featured a non-porous dense layer containing polygonal grains, as also observed on membranes studied by Shih et al. ${ }^{18}$, which increases resistance to the flux. The formation of these grains on the membrane surface is due to the increase of polymer concentration in the interface between 


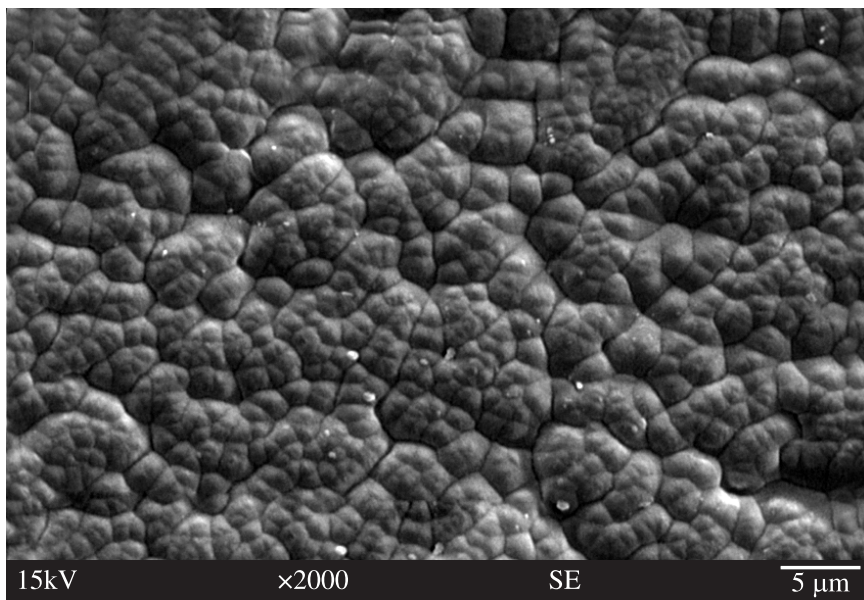

(a)

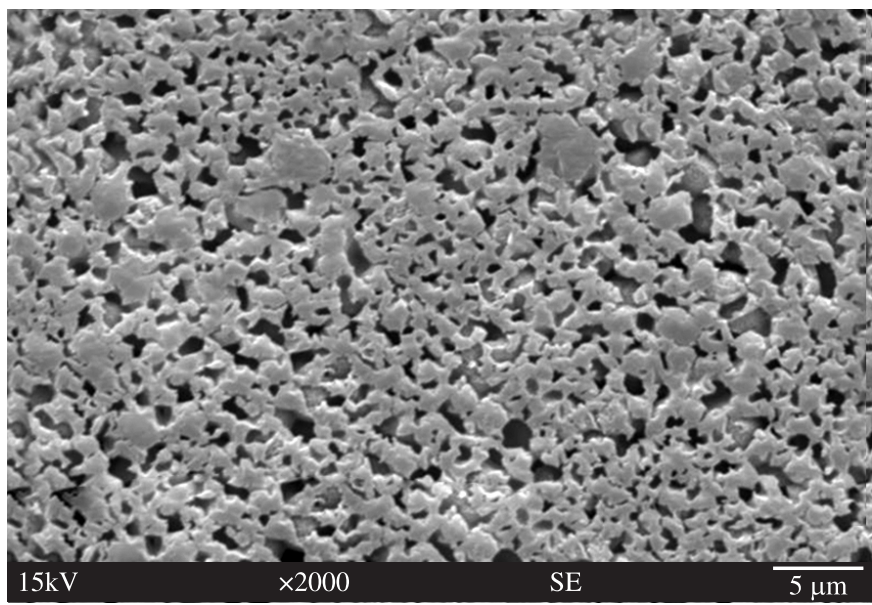

(b)

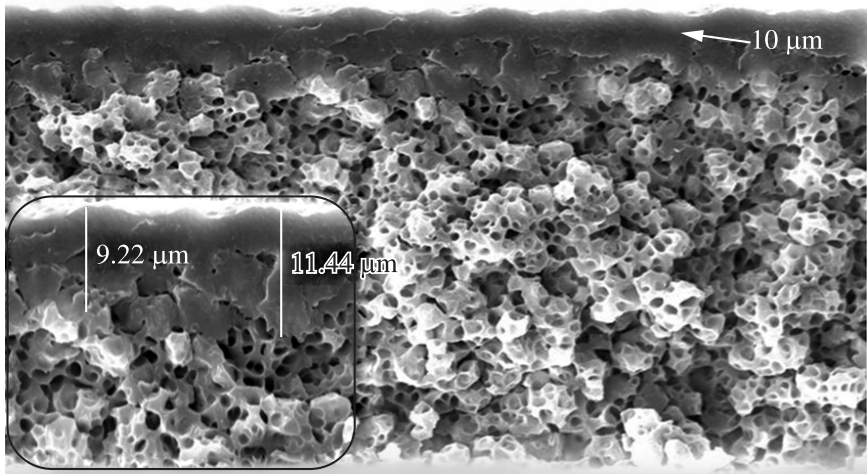

$15 \mathrm{kV}$

$\times 1000$

SE

$10 \mu \mathrm{m}$

(c)

Figure 1. Morphology of membrane M-FA: a) top surface; b) bottom surface; c) cross section and morphology of membrane M-HCl; d) top surface; e) bottom surface; and f) cross section.

the coagulation bath and the polymer solution soon after contact with water ${ }^{10}$, which is a fast coagulant for the polymer.

The morphology of the bottom surface of both the membranes is presented in Figure $1 \mathrm{~b}$ and 1e. A large number of liquid micelles have to nucleate directly on the surface of the glass plate. As a result of the structure formation against the glass plate, the production of pores seems to have been interrupted and the feature observed is of a flattened surface.

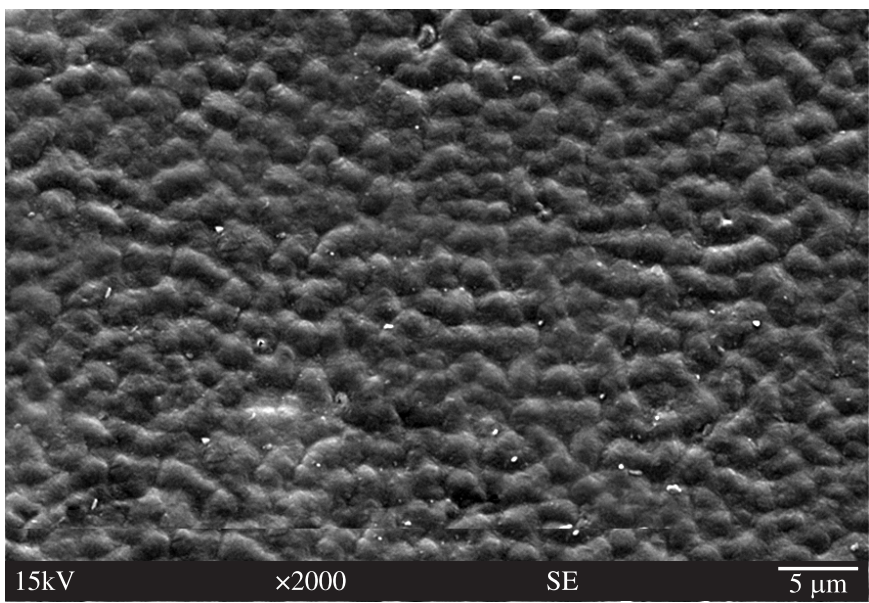

(d)

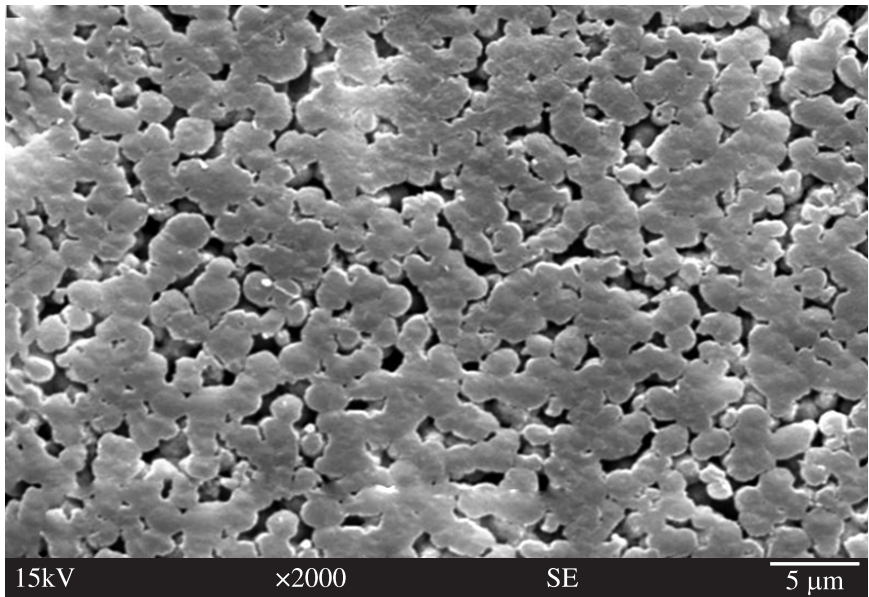

(e)

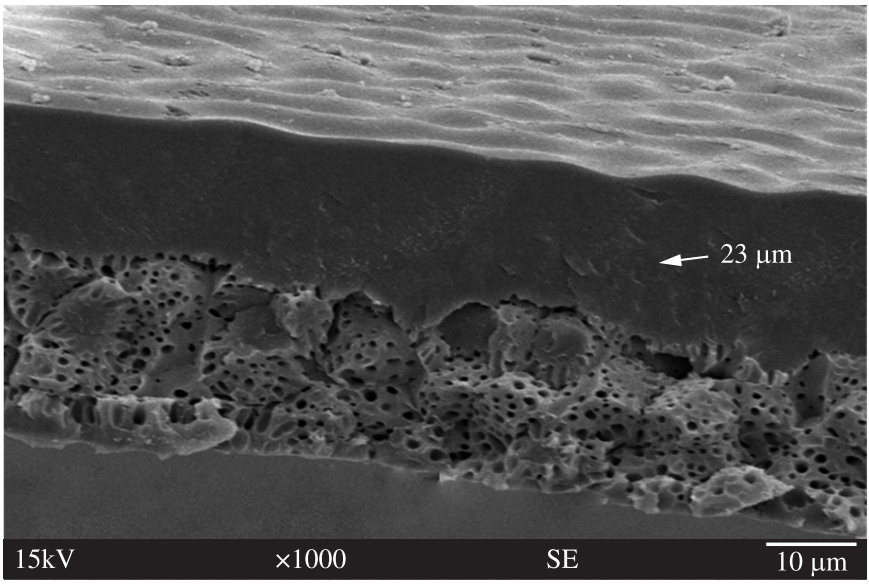

(f)
As observed in Figure 1c and 1f, the cross section of the asymmetric membranes shows a porous substructure and a dense top layer. The morphology found in the membranes prepared in this work with FA is very similar morphologies described by the earlier authors ${ }^{7,10}$. The thickness of the dense layer of membranes was measured by one a software tool of microscope. In membranes prepared in formic acid, the thickness of the dense layer was $10.3 \pm 1.5 \mu \mathrm{m}$, whereas in the $\mathrm{M}-\mathrm{HCl}$ membrane was around $23.1 \pm 1.2 \mu \mathrm{m}$. 


\subsection{Formation mechanisms of PA 66 membranes structures}

The dense top layer and the porous sublayer are formed by different mechanisms, generating different morphologies. As soon as the polymer solution is immersed into the coagulation bath, the top layer formed first on the interface between the coagulation bath and the polymer solution, as a result of the high polymer concentration on the interface.

According to Chuang et al. ${ }^{21}$, during the formation of the sublayer, the precipitation of the top layer creates an additional barrier to the mass transfer between sublayers and the coagulation bath. Subsequent to the formation of the dense layer, the solvent outflow rate to the coagulation bath is reduced. At that moment, the coagulant diffuses through the top layer down to the sublayers for the formation of the nuclei that correspond to the polymer-lean phase. The nuclei grow, originating pores, and their walls are formed from the polymer-rich phase. Thus, the cellular morphology found occurs in the membrane sublayers supporting the dense top layer during its formation process.

In regard to the membrane prepared with $\mathrm{HCl}$, it was necessary to evaporate the solvent (in the present case 60 minutes) before the immersion in the coagulation bath. Such fact suggests that during evaporation there is a greater concentration of polymer on the surface, increasing the thickness of the dense layer. When FA is used, the membrane is formed by immersion into the non-solvent (immersion precipitation) without an evaporation stage, resulting in a thin dense layer.

However, the casting solution prepared from $\mathrm{PA} 66 / \mathrm{HCl}(\mathrm{M}-\mathrm{HCl})$ is evaporated to film formation, suggesting that this long stage of evaporation (60 minutes) favors the formation of thick dense layer compared with the M-FA membrane, which is evaporated for 5 minutes.

\subsection{Water content and porosity}

The water content is an important parameter for the membrane characterization and it is indirectly related to the hydrophilicity degree and directly related to the porosity of the membrane ${ }^{11}$. The percentage values of water absorbed in 24 hours are reported in Table 2. The membranes prepared in formic acid showed greater water absorption and greater porosity. The M-FA membrane absorbed approximately $60 \%$ of water, whereas $\mathrm{M}-\mathrm{HCl}$ membrane absorbed just about $20 \%$. In parallel to those results, the total porosity of the membranes was approximately $50 \%$ in M-FA membrane and approximately $15 \%$ in $\mathrm{M}-\mathrm{HCl}$ membrane.

The pores in the sublayer are responsible for accommodating water molecules in the membranes ${ }^{12}$. The lower value of water absorption and, consequently, of porosity may be a result of the morphology of the membrane prepared with $\mathrm{HCl}$, in which the thickness of dense layer is relatively high, as observed in the microscopy shown in Figure 1.

\subsection{Pure water flux}

The membranes are subjected to water permeation carried out for 2 hours at a constant transmembrane pressure of $101 \mathrm{kPa}$. The water permeation of PA 66 membranes was investigated, as shown in Figure 2. The membranes showed a stable behavior with small variations in pure water flux.

It is shown that the flux declines gradually due to hydraulic compaction with time. This is due to the fact that walls of pores become closer, denser and uniform resulting in reduction in pore size as well as the flux during compaction ${ }^{11,12}$. The pure water flux value of $39 \mathrm{Lm}^{-2} / \mathrm{h}$ was obtained for M-FA membrane and $5.5 \mathrm{Lm}^{-2} / \mathrm{h}$ for $\mathrm{M}-\mathrm{HCl}$ membrane in the end of 120 minutes. This lower value may be attributed to the higher thickness of dense layer, as discussed
Table 2. Parameters for PA 66 membranes characterization.

\begin{tabular}{cccc}
\hline Membrane & $\begin{array}{c}\text { Water content } \\
(\%)\end{array}$ & $\begin{array}{c}\text { Porosity } \\
(\%)\end{array}$ & $\begin{array}{c}* \text { Pure water } \\
\text { flux }\left(\mathrm{Lm}^{-2} \mathrm{~h}^{-1}\right)\end{array}$ \\
\hline $\mathrm{M}-\mathrm{FA}$ & $63 \pm 3$ & $53 \pm 3$ & 39 \\
$\mathrm{M}-\mathrm{HCl}$ & $22 \pm 4$ & $15 \pm 2$ & 5.5 \\
\hline
\end{tabular}

* Flux value in the end of 120 minutes.

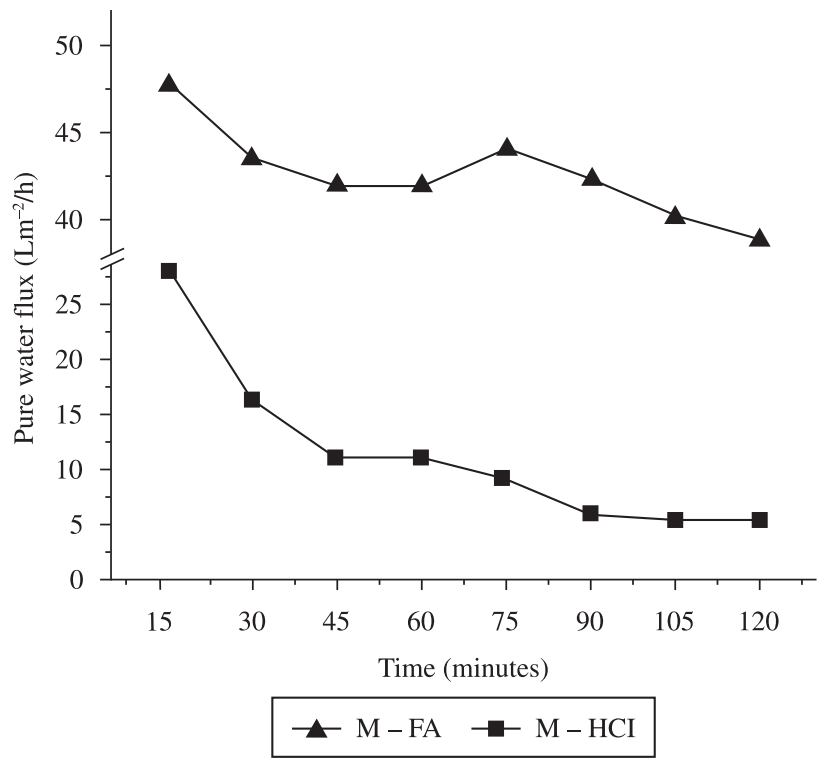

Figure 2. Pure water flux of M-FA and $\mathrm{M}-\mathrm{HCl}$ membranes.

previously. According to Mulder ${ }^{22}$, increasing the thickness of dense layer increases the resistance to the water flux.

Morphology and structure of membranes (top layer and sub layer) also play a key role in this regard. Lastly, the solvents (FA and $\mathrm{HCl}$ ) may also be considered as important factor in the membranes preparation, because they strongly affect the morphology and properties of a membrane.

\section{Conclusions}

The conditions established for the preparation of PA 66 membranes through the process of phase inversion strongly influence the membrane final structure. The use of $\mathrm{FA}$ and $\mathrm{HCl}$ as the solvents for the PA 66 showed that the morphology obtained in the films is an asymmetric structure, but presented a significant difference in thickness of the dense layer.

The greater thickness of dense layer in membranes prepared with $\mathrm{HCl}$ directly influenced as to result the lower water absorption, total porosity and pure water flux when compared to membranes prepared with formic acid.

When comparing the best solvent among the membranes, the use of FA resulted in membranes with the thinnest dense layer and smallest resistance to water flux. Nevertheless, these results are not sufficient to exclude the use of $\mathrm{HCl}$ as solvent for PA66 in the preparation of membranes.

\section{References}

1. Scott K. Handbook of industrial membranes. Oxford: Elsevier Advanced Tecnology; 1995.

2. Carvalho RB, Borges CP and Nóbrega R. Formação de membranas planas celulósicas por espalhamento duplo para os processos de nanofiltração e osmose inversa. Polímeros. 2001; 11:65-75. 
3. Yao CW, Burford RP, Fane AG and Fell CJD. Effect of coagulation conditions on structure an properties of membranes from aliphatic polyamides. Journal of Membrane Science. 1988; 38:113-125. http://dx.doi.org/10.1016/S0376-7388(00)80874-1

4. Rawajfeh AE. Polyamide-based composite membranes: Part 1. Preparation and characterization. Desalination. 2005; 179:265-272. http://dx.doi.org/10.1016/j.desal.2004.12.024

5. Rawajfeh AE, Al-Salah HA, Al-Shamaileh E and Donchev D. Polyamidebased composite membranes: Part 2. Interaction, crystallization and morphology. Desalination. 2008; 227:120-131. http://dx.doi. org/10.1016/j.desal.2007.06.020

6. Torres MR, Soriano E, Abajo J and De La Campa JG. Comparative study of the behaviour of experimental polyamide UF membranes. The effect of polyvinylpyrrolidone used as an additive. Journal of Membrane Science. 1993; 81:31-42. http://dx.doi.org/10.1016/0376-7388(93)85029-V

7. Leite AMD, Araújo EM, Lira HL, Barbosa R and Ito EN. Obtenção de Membranas Microporosas a partir de Nanocompósitos de Poliamida 6/ Argila Nacional. Parte 1: Influência da Presença da Argila na Morfologia das Membranas. Polímeros. 2009; 19:271-277.

8. Bindal RC, Hanra MS and Misra BM. Novel solvent exchange cum immersion precipitation technique for the preparation of asymmetric polymeric membrane. Journal of Membrane Science. 1996; 118:23-29. http://dx.doi.org/10.1016/0376-7388(96)00073-7

9. Young TH, Huang YH and Chuang WY. Effect of evaporation temperature on the formation of particulate membranes from crystalline polymers by dry-cast process. European Polymer Journal. 2002; 38:63-72. http://dx.doi.org/10.1016/S0014-3057(01)00183-5

10. Lin DJ, Chang CL, Lee CK and Cheng LP. Fine structure and crystallinity of porous Nylon 66 membranes prepared by phase inversion in the water/formic acid/Nylon 66 system. European Polymer Journal. 2006; 42:356-367. http://dx.doi.org/10.1016/j.eurpolymj.2005.07.007

11. Chakrabarty B, Ghoshal AK and Purkait MK. Effect of molecular weight of PEG on membrane morphology and transport properties. Journal of Membrane Science. 2008; 309:209-221. http://dx.doi.org/10.1016/j. memsci.2007.10.027

12. Chakrabarty B, Ghoshal AK and Purkait MK. Preparation, characterization and performance studies of polysulfone membranes using PVP as an additive. Journal of Membrane Science. 2008; 315:36-47. http://dx.doi. org/10.1016/j.memsci.2008.02.027
13. Saljoughi E, Sadrzadeh M and Mohammadi T. Effect of preparation variables on morphology and pure water permeation flux through asymmetric cellulose acetate membranes. Journal of Membrane Science. 2009; 326:627-634. http://dx.doi.org/10.1016/j.memsci.2008.10.044

14. Yoo SH, Kim JH, Jho JY, Won J and Kanga YS. Influence of the addition of PVP on the morphology of asymmetric polyimide phase inversion membranes: effect of PVP molecular weight. Journal of Membrane Science. 2004; 236:203-207. http://dx.doi.org/10.1016/j. memsci.2004.02.017

15. Poletto P, Duarte J, Thürmer MB and Zeni M. Polyamide 66 membranes with PVP addition prepared by phase inversion. Desalination and Water Treatment. 2011; 27:76-80. http://dx.doi.org/10.5004/dwt.2011.2055

16. Barzin J and Sadatnia B. Theoretical phase diagram calculation and membrane morphology evaluation for water/solvent/polyethersulfone systems. Polymer. 2007; 48:1620-1631. http://dx.doi.org/10.1016/j. polymer.2007.01.049

17. Thomas JL, Olzog M, Drake C, Shih CH and Gryte C. Polyamide membrane precipitation studied by confocal backscattering microscopy. Polymer. 2002; 43:4153-4157. http://dx.doi.org/10.1016/S00323861(02)00250-1

18. Shih CH, Gryte $\mathrm{C}$ and Cheng LP. Morphology of membranes formed by the isothermal precipitation of polyamide solutions from water/ formic acid systems. Journal of Applied Polymer Science. 2005; 96:944-960. http://dx.doi.org/10.1002/app.21545

19. Zeni M, Riveros R, Souza JF, Mello K, Meireles C and Rodrigues GF. Morphologic analysis of porous polyamide 6,6 membranes prepared by phase inversion. Desalination. 2008; 221:294-297. http://dx.doi. org/10.1016/j.desal.2007.03.012

20. Guan R, Dai H, Li C, Liu J and Xu J. Effect of casting solvent on the morphology and performance of sulfonated polyethersulfone membranes. Journal of Membrane Science. 2006; 277:148-156. http://dx.doi. org/10.1016/j.memsci.2005.10.025

21. Chuang W-Y, Young T-H, Chiu W-Y and Lin C-Y. The effect of polymeric additives on the structure and permeability of poly(vinyl alcohol) asymmetric membranes. Polymer. 2000; 41:5633-5641. http://dx.doi. org/10.1016/S0032-3861(99)00818-6

22. Mulder M. Basic principles of membrane technology. 2th ed. Dordrecht: Kluwer Academic Publishers; 1996. 